Bond University

Research Repository

\title{
Establishing an evidenced-based dietetic model of care in haemodialysis using implementation science
}

Mackay, Hannah J; Campbell, Katrina L; van der Meij, Barbara S; Wilkinson, Shelley A

Published in:

Nutrition and Dietetics

DOI:

10.1111/1747-0080.12528

Licence:

Other

Link to output in Bond University research repository.

Recommended citation(APA):

Mackay, H. J., Campbell, K. L., van der Meij, B. S., \& Wilkinson, S. A. (2019). Establishing an evidenced-based dietetic model of care in haemodialysis using implementation science. Nutrition and Dietetics, 76(2), $150-157$. https://doi.org/10.1111/1747-0080.12528

\section{General rights}

Copyright and moral rights for the publications made accessible in the public portal are retained by the authors and/or other copyright owners and it is a condition of accessing publications that users recognise and abide by the legal requirements associated with these rights.

For more information, or if you believe that this document breaches copyright, please contact the Bond University research repository coordinator. 


\section{Establishing an evidenced-based dietetic model of care in Haemodialysis using implementation science}

Running title: EBP haemodialysis dietetic service implementation

\section{Author names}

Hannah J Mackay ${ }^{1}$, Katrina L Campbell ${ }^{2}$, Barbara S van der Meij ${ }^{1,2,3}$, Shelley A Wilkinson ${ }^{1,3}$.

Hannah J Mackay, BNutr\&Diet (Hons), APD, Dietitian, Mater Health

Katrina L Campbell, BNutr\&Diet (Hons), PhD, Associate Professor Bond University, AdvAPD, Senior Research Fellow Queensland Health

Barbara S van der Meij, BNutri\&Diet, Msc Nutrition \& Health, PhD, Conjoint Senior Research Dietitian, Mater Health and Bond University

Shelley A Wilkinson, BSc, BPsych (Hons), GradDipNutr\&Diet, PhD, AdvAPD, Senior Research Dietitian, Mater Health/Mater Research

\section{Author affiliations}

${ }^{1}$ Department of Dietetics \& Foodservices, Mater Health, South Brisbane, Queensland ${ }^{2}$ Faculty of Health Sciences and Medicine, Bond University, Robina, Gold Coast, Queensland ${ }^{3}$ Mater Research Institute -University of Queensland, Brisbane, Queensland

\section{Authorship Declaration}

HM lead the project and collected data. HM and BM analysed data. KC and SW supervised the project. All authors contributed to interpretation of results, and revision of the manuscript. All authors are in agreement with the manuscript and declare that the content has not been published elsewhere. published in final form at https://doi.org/10.1111/1747-0080.12528. 
The authors would like to thank Dr. Michael Burke and Dr. Richard Baer (Department of Nephrology, Mater Health), Shimbie Lewis (Fresenius Medical Care), Anne Jackson and Kelly Willersdorf (Mater Education), Cameron Hurst and Satomi Okano (QIMR Berghofer Medical Research Institute), and Mater Foundation.

\section{Funding statement}

This research did not receive any grant funding.

\section{Conflicts of Interest statement}

The authors declare no conflict of interest.

Word count: 3851

Number of tables: 2

Number of figures: 1 published in final form at https://doi.org/10.1111/1747-0080.12528 


\section{Abstract}

Aim: To establish an evidence-based dietetics service in an in-centre haemodialysis unit utilising Implementation Science.

Methods: The service was developed through the Knowledge-to-Action Framework. The steps of the Action Cycle were addressed through a literature review, identification of evidence-based guidelines, benchmarking, and local staff engagement. The theoretical domains framework (TDF) was used to identify barriers/enablers, and behaviour change wheel to determine appropriate interventions. To monitor, evaluate outcomes, and assess sustained knowledge use we employed multidisciplinary team engagement and database use. Audit data were collected at baseline, 6 and 12 months on nutrition assessment (Patient-Generated Subjective Global Assessment), intervention timeliness, and alignment to dietetic workforce recommendations. Descriptive statistics, McNemar tests, and a linear mixed model were applied.

Results: Barriers existed in the knowledge, skills, environmental context and resources TDF domains. Suitable interventions were identified with training on nutritional management of haemodialysis patients delivered to 148 nurses, and nutrition management recommendations summarised into local procedural resources. A database to prompt and monitor outcome measures was created and indicated that over 18 months post service commencement, eligible patients received nutrition assessment at least 6-monthly, aligning with recommendations. Prevalence of malnutrition was $28 \%(n=9 / 32)$ at baseline, $23 \%(n=5 / 22)$ at 6 months, and $20 \%$ $(n=4 / 20)$ at 12 months $(p=0.50)$.

Conclusions: We demonstrated benefits to service development and implementation with implementation science providing a structured and methodical approach to translating guidelines into practice. Development of training, resources and prompts for outcome measures has supported the establishment of an evidence-based dietetics service in a haemodialysis unit.

Key words: Renal, clinical nutrition and dietetics, malnutrition, evidence based practice

\section{Introduction}

2 The increasing prevalence of Chronic Kidney Disease (CKD) is a global health problem

3 causing high burden on patients and the health care system. In Australia prevalence of 
4 CKD is around $10 \%$ which equates to approximately 1.7 million Australian adults with

5 CKD. ${ }^{1,2}$ Nutrition care is vital for all people with CKD, not only for assisting in management

6 of electrolyte disturbances, fluid balance, mineral and bone disorders, but also to prevent

7 and manage protein-energy wasting (PEW). ${ }^{3} \mathrm{PEW}$ is highly prevalent in haemodialysis

8 patients (up to $64 \%),{ }^{4}$ and is predictive of increased morbidity and mortality in CKD. ${ }^{3,5}$

9 Therefore, monitoring and management of PEW is essential in the haemodialysis

10 population.

Various national and international evidence-based guidelines are available to guide nutrition management during haemodialysis., ${ }^{3,6-11}$ Additionally, there are Australian workforce recommendations ${ }^{12}$ and state government demand-management protocols known as "Frameworks for Effective and Efficient Dietetics Services" (FEEDS) ${ }^{13}$ to guide practice. Implementation of these evidence-based nutrition guidelines is associated with improved nutrition status and reduced rates of malnutrition which is linked to mortality in haemodialysis patients..$^{14,15}$

Despite the existence of evidence-based nutrition guidelines, failure to routinely translate evidence into clinical practice is a common finding in health services. ${ }^{16}$ Awareness and dissemination of guidelines alone does not always change practice and the assessment of influencing factors (barriers and enablers) and implementation and evaluation design should be systematic and theory-driven. ${ }^{17,18}$ Barriers for implementing CKD evidencebased guidelines have been identified in surveys with specialist renal dietitians in Australia and New Zealand, with barriers being a perceived lack of time, skills/self-efficacy, and inefficient referral systems relating to lower rates of guideline implementation. ${ }^{19}$ Inadequate staffing has been identified as a barrier in the provision of appropriate care with various renal services having inadequate staffing allocations to meet recommendations. ${ }^{12}$ 
This paper describes the planning and implementation of a new nutrition service at an incentre haemodialysis unit established at a metropolitan tertiary hospital in Queensland. The process undertaken to translate haemodialysis nutrition guidelines into practice in the establishment of an evidence-based haemodialysis model of care used an Implementation Science approach. Specifically, this project aimed to follow the Knowledge-to-Action (KTA) cycle,$^{20}$ theoretical domains framework (TDF) $)^{21}$ and behaviour change wheel $(\mathrm{BCW})^{22}$ to apply evidence in a local setting following an assessment of barriers and enablers, designing of effective interventions supported by routine monitoring, and evaluation processes.

\section{Methods}

This project was commenced in September 2016 to meet the needs of a new in-centre haemodialysis service, with a total of twelve dialysis chairs for both public and private health funded patients, available for morning and evening shifts, opening November 2016. To develop, implement, and evaluate our haemodialysis model of care we applied the KTA which is an iterative approach that allows building (Knowledge Creation) and application of knowledge (Action Cycle). ${ }^{23}$ The steps of the Action Cycle can occur sequentially or concurrently and involve identification of the problem, assessing knowledge use determinants, evaluating the impact of knowledge use or outcomes, and ensuring sustainability. ${ }^{20}$ In this project assessment and intervention selection required use of the integrative $\mathrm{TDF}^{21}$ and $\mathrm{BCW}{ }^{22}$ the TDF as a system for defining barriers, and the $\mathrm{BCW}$ as a system for guiding decision-making around designing behaviour change interventions based on the barriers. ${ }^{22,24}$

The action cycle process of problem identification involves reviewing and selecting knowledge, then adapting knowledge to the local context. Therefore, renal nutrition guidelines were identified by a literature search through Pubmed, CINAHL, 
key guidelines were later included up to twelve years after publication..$^{3,6,7,9-11,25,26}$ We systematically mapped our clinical service and collated the best available evidence for the clinical area using Nutrition Care Process Terminology. ${ }^{27}$ Service mapping and comparisons included benchmarking with external haemodialysis centres regarding models of care such as current inpatient and outpatient dietetic procedures, referral and monitoring processes, and training programs. Engagement with management and staff internal (Nephrologists, Nursing, Mater Education) and external (Fresenius - a service partner) was undertaken to define the wider service plan, including expected capacity with patient numbers, time frames for dialysis and possible service expansion plans. Assessment of knowledge use determinants, specifically barriers to knowledge use, was conducted through clinic observation, along with team discussion with key partners including management, Nephrologists, and local dietitians, with information collection about current practices, the service plan, and identification of potential barriers prior to haemodialysis service commencement. Barriers were categorised and defined using the TDF which includes the twelve domains; knowledge, skills, social/professional role and identity, beliefs about capabilities, beliefs about consequences, motivation and goals, memory and decision processes, environmental context and resources, social influences, emotion, behaviour regulation, and nature of the behaviours. Application of the BCW was to be used to determine intervention appropriateness for the barriers and enablers identified with the TDF domains. ${ }^{22}$

In order to monitor knowledge use, evaluate outcomes, and sustain knowledge use a database was created for dietitian use, and analysed six-monthly. Data was collected as an audit to define the population and demonstrate effectiveness of the service change. Data included outcome measures of malnutrition prevalence as assessed with the PG-SGA category (categorised as A: well-nourished, B: moderately malnourished, or C: severely malnourished), and numerical score (range 0 to 50 , with lower score indicating reduced malnutrition risk), ${ }^{28}$ timeliness of intervention after commencing haemodialysis, and overall 
dietitian time allocation and number of occasions of service as extracted from the Team Allied Health Data Information System. The dietitian full-time equivalent (FTE) for the haemodialysis unit was compared to those in workforce recommendations suggesting 1 FTE for every 100 haemodialysis patients. ${ }^{12}$ The dietitian would also see patients undergoing haemodialysis short-term or who were admitted on inpatient wards, however these were not included in general data collection.

\section{A database was developed for the dietitian to record patient demographics, PG-SGA} scores, consult dates and prompts for future reviews for patients attending the haemodialysis service. There were automatic referrals for all new patients to the service, and reviews were determined by the dietitian or requested from the multidisciplinary team. All patients that attended the service during the 18 months following opening were assessed including with a PG-SGA, with an aim to be completed within one month of commencing haemodialysis and a minimum of six-monthly thereafter as usual care. Data were audited and analysed six-monthly however data were excluded from analysis for patients that were dialysing short-term, palliative, admitted to alternative tertiary hospitals, or discharged from the service in less than six months.

Patient characteristics including age, gender, and public or private funding source, were presented using descriptive statistics, with means and standard deviations used for continuous variable, if normally distributed, and median and interquartile ranges otherwise. Categorical variables were described using counts and percentages. For the outcome, PGSGA category (A: well-nourished, or, B and C: moderately and severely malnourished) as a binary variable, we considered baseline and after 12 months with McNemar test used to test for an association. As outcome PG-SGA score was both continuous and repeatedly measured over time we used a linear mixed model to account for the correlated longitudinal nature of data. All analysis was conducted using SPSS for Windows version 24. A significance level of 0.05 was used throughout all inferential analysis. 
116 This study received exemption from ethical approval from the hospital's Human Research

117 Ethics Committee (HREC/18/MHS/90).

\section{Results}

120 Assessment of barriers identified the main TDF domains to be knowledge, skills, and

121 environmental context and resources as detailed further in Table 1. Interventions were

122 developed to address barriers with appropriateness determined from use of the BCW. ${ }^{24}$

123 These interventions have been operationalised as various strategies shown in the final

124 column in Table 1.

125 Evidence-based guidelines for nutritional management of haemodialysis patients were

126 identified and summarised into a local document to assist the dietitian gain knowledge and

127 guide the nutrition care process and training content. ${ }^{3,6-11}$

Training was a key intervention function to address knowledge and skills barriers for nursing and dietetics. This was undertaken in ten identical face-to-face training workshops conducted with a total of 148 nursing staff from both public and private hospital sectors as haemodialysis patients would be both public and privately funded. The nutrition component of the workshops involved a 25 -minute presentation with session topics including the various nutrition components for haemodialysis patients, the role of the dietitian and when to refer patients to the dietitian. The nutrition component was developed alongside various other components relevant to the care of patients with chronic kidney disease including the patient journey, pharmacological considerations, nursing and fistula care. The workshop was complimented by development of an online learning guide for nursing staff which is being reviewed by a team of health professionals including doctors, clinical educators, nursing staff, pharmacists, and the renal dietitian, for future education program use. This learning guide included nutritional management of haemodialysis patients, pathways for

142 dietitian referrals, along with other aspects of nursing care for haemodialysis patients. 
144 A one-off presentation was also prepared for professional development of all Nutrition and

145 Dietetic department dietitians. This presentation described the dialysis unit including

146 number of dialysis chairs, potential patient numbers, timing of dialysis, and the role of

147 nutrition in haemodialysis with NCP components expanded on from the nursing nutrition

148 module.

150 Service design included involvement in multi-disciplinary processes such as meetings,

151 monthly blood review (with Nephrologist, Pharmacist, Nursing), and education strategies for

152 both staff and patients. The dietitian was involved in mentoring and peer reviewing to

153 further ensure knowledge and skills barriers were addressed. The haemodialysis dietetic

154 service was also integrated into a Nutrition and Dietetic department strategy of regular

155 evaluation and reporting.

156

157 Figure 1 shows the patient flow during the 18-months of haemodialysis service. There was

158 a total $n=33$ eligible patients that attended the haemodialysis service over the eighteen

159 months following service commencement. Outcome measures were collected with $n=32$ at

160 baseline, and $n=22$ and $n=20$ at six and 12 months respectively. There were incomplete

161 malnutrition data for a total of two patients ( $n=1$ at baseline, and $n=1$ at six-month follow-

162 up), and a total of $n=27$ were excluded over the period from November 2016 to May 2018,

163 with $63 \%(n=17 / 27)$ that left the service with continued dialysis at alternative sites. Patients

164 that did not meet eligibility were still seen by the dietitian as part of usual care however data

165 were not included in analysis.

166

167 The mean age of the haemodialysis population was $63.7(\mathrm{SD}=16.8)$ years and $52 \%$

$168(n=17 / 33)$ of these patients were male. A majority of patients $(93.9 \%, n=31 / 33)$ were public

169 patients. A total of $48.5 \%(n=16 / 33)$ of the patients included were new to dialysis;

170 commencing dialysis for the first time at the service. In the initial 18 months following

This is the peer reviewed version of the following article: Mackay, H. J., Campbell, K. L., van der Meij, B. S., \& Wilkinson, S. A. (2019). Establishing an evidenced-based dietetic model of care in haemodialysis using implementation science. Nutrition and Dietetics, 76(2), 150-157, which has been published in final form at https://doi.org/10.1111/1747-0080.12528.

This article may be used for non-commercial purposes in accordance with Wiley Terms and Conditions for Use of Self-Archived Versions 
service establishment, $100 \%$ of patients received dietetics assessment as part of usual care.

174 All haemodialysis patients were seen for nutrition assessment including a PG-SGA in the 6monthly time-points and a priority was placed on nutrition assessment of newly commencing haemodialysis patients.

Initial assessment with use of PG-SGA was completed $24.0(S D=23.4)$ days after commencing at the dialysis unit, with repeat measures at $6.0(\mathrm{SD}=1.5)$ months, and 11.8 $(S D=1.6)$ months. Included within the 12-month PG-SGA data were two outliers that received assessment of PG-SGA at 9-months post- commencing at the service however they were included as nutrition guidelines recommend minimum of six-monthly assessment. Of patients new to dialysis, $88 \%(n=14 / 16)$ were seen within one month of commencing dialysis.

Malnutrition prevalence is detailed in Table 2. There was no statistical change in malnutrition categories or score over the 12 months $(P=0.45)$, with the majority of patients (72-80\%) being well nourished from commencement and at all time-points. While a decrease in PG-SGA score was seen in our sample, with an average PG-SGA score of 6.2 (95\% Cl: 4.6-7.8) at baseline, $5.3(95 \% \mathrm{Cl}: 3.5-7.2)$ at six-months, and 4.8 (95\% Cl: 2.8$6.7)$ at 12 months, this was not statistically significant $(P=0.49)$.

193 The dietitian was allocated initially a 0.3 FTE to provide service for a total of 23 patient 194 (equivalent of 1.30 FTE to 100 haemodialysis patients) and this increased over the 18 195 months to 0.4 FTE for a total of 29 patients (equivalent of 1.38 FTE to 100 haemodialysis 196 patients), however the allocation also included the additional time provided for service development and inpatient renal nutrition care. On average over the 18 month period greater than $87 \%$ of dietitian time was face-to-face or patient-related activity. There was an 
increased review frequency for patients that were malnourished, requiring weight management for renal transplant eligibility, requiring nutrition education and counselling due to nutrition-related abnormal biochemistry or fluid control.

202

\section{Discussion}

Following an IS approach we successfully developed, implemented and evaluated an evidence-based haemodialysis dietetic service. This approach allowed for targeted nutrition education and training interventions for staff, and clearly defined dietetic service processes and procedures, with NCP components detailed and adapted for the local context. A mechanism prompting routine monitoring of outcomes has also been adopted into usual care, allowing for easier regular evaluation with continuation of the KTA cycle.

Subsequently, the development and implementation of the service has resulted in haemodialysis patients receiving nutrition assessment within appropriate time-frames (a minimum of 6-monthly) as recommended in evidence-based guidelines. ${ }^{9}$ The service has had sufficient dietetic staffing levels, with additional FTE provided above the workforce recommendations allowing for service development and expected service growth. The initial education and training with nursing is planned to be repeated and further review of the online module to assist with sustaining knowledge and skills.

218 For patients attending the evidence-based haemodialysis dietetic service, the majority (72$80 \%$ ) have been well-nourished. The malnutrition prevalence in the current population was low from commencement and through all included time-points. The reason for malnutrition prevalence prior to attending the service can not be commented on however alternative variables impacting malnutrition prevalence may be an area for further research. The

223 literature suggests malnutrition prevalence in the haemodialysis populations of up to $64 \%{ }^{4}$

224 however implementation of evidence-based practice in previous studies has shown beneficial clinical outcomes on malnutrition prevalence. ${ }^{15}$ Another study implementing evidence-based practice in a haemodialysis population showed a decrease in malnutrition 
227 prevalence from $14 \%$ at baseline to $3 \%$ in three years. ${ }^{15}$ This study had similar

228 demographics, however had a higher ratio of private facility patients, and excluded patients

229 that had been undergoing dialysis for less than three months where the current study

230 included patients new to haemodialysis. The PG-SGA data assists in explaining the

231 population, aligns with similar research and as many renal services routinely monitor

232 malnutrition prevalence six-monthly, the data may assist for comparison and

233 benchmarking.

234

235 Although initial outcome measures were aiming to achieve the minimum of 6 -monthly

236 assessment, there was further collaboration and attendance at monthly blood reviews and

237 multi-disciplinary meetings to ensure avenues for communication, close monitoring of

238 biochemistry, and prompting for more regular reviews if indicated. This open

239 communication is seen as an enabler for the referral process which has otherwise been

240 suggested as a potential barrier in previous research. ${ }^{19}$ Furthermore, support from

241 management and higher dietetic FTE than the 1:100 haemodialysis patients recommended

242 in workforce guidelines assisted in the ability to use the IS approach and was an enabler to

243 perceived time barriers that have been identified by other renal dietitians for nutrition

244 guideline implementation.

245 However, during the initial 6-month period there were two occasions of nutrition

246 assessment of new dialysis patients being prolonged further than the one month suggested

247 by Fouque et $\mathrm{al}^{8}$. This was identified and created further understanding of processes and

248 the potential barrier of reduced workforce over public holidays and the need to ensure

249 appropriate predictions for these times.

250

251 The current dietetics service aligns with the Framework for Effective and Efficient Dietetic

252 Services (FEEDS) recommending patients be seen a minimum of 6-monthly with use of a

253 nutrition assessment tool such as SGA or PG-SGA. ${ }^{13}$ The FEEDS document also prioritises

254 referral reasons, recommends experienced dietitians or mentoring, and similarly provides published in final form at https://doi.org/10.1111/1747-0080.12528. 
277 As part of our department's wider commitment to delivering evidence-based care through

references for evidence-based guidelines, all of which were incorporated into local work area resources. However, this study provides further detail on implementation of evidencebased guidelines into dietetic practice with the use of frameworks as an example to allow for an iterative process for others.

The strength of this study is the systematic application of frameworks such as the KTA, TDF and the BCW in planning the implementation of the new model of care. Use of theory and frameworks has been shown to be more effective than projects based on intuition..$^{29,30}$ Further strengths include the structured approach to implementation of evidence-based guidelines in service development, which allows for future research, wider collaboration, and assistance in streamlining services. This IS approach may provide an example for other similar dietetic services establishing or implementing an evidenced-based model of care. Limitations include the small sample size which impacts the ability to detect statistically significant changes in measured outcomes. However, these will continue to be routinely evaluated to obtain an ongoing measure of our service effectiveness and will allow planning of data-informed, iterative service changes, as required. Further limitations relate to the lack of access to the evaluation of knowledge transfer to nursing staff after training, patient satisfaction and consumer engagement during the service development. However, this has been acknowledged and will be completed in future training and education, and service provision has also included a structured plan for patient satisfaction and consumer engagement. continual application of the KTA cycle we plan to monitor the services identified outcomes 6-monthly and develop our service and incorporate new evidence into our practice as literature becomes available, as required. Furthermore, it is acknowledged that guidelines are only as robust as the research that informs them and call for ongoing Knowledge published in final form at https://doi.org/10.1111/1747-0080.12528. 
282 Creation activities to enhance the delivery of evidence-based nutrition care in

283 haemodialysis.

284

285 Conclusion

286 We have demonstrated the benefits to service development and implementation that can

287 results from the use of IS frameworks and models (KTA, TDF, BCW) to translate evidence-

288 based guidelines into practice. These tools have enabled a structured and methodical

289 approach to both establishment and continued implementation of the service over time. Key

290 interventions including training, local resource development, and a working database

291 embedding monitoring and evaluation of outcome measures into practice has resulted in

292 maintenance of nutrition status over the 18 months following service commencement.

293 There is a plan to continue these processes with ongoing monitoring and evaluation and

294 use of these frameworks and implementation science as the service grows. Further

295 research needs to be conducted in evaluation of training programs, consumer feedback,

296 and alternative variables impacting malnutrition prevalence. 


\section{References}

1 Australian Institute of Health and Welfare. Chronic kidney disease compendium [Web report]; 2017. (Available from: https://www.aihw.gov.au/reports/chronic-kidneydisease/chronic-kidney-disease-compendium/data, accessed 2 September 2018).

2 International Society of Nephrology. Global Kidney Health Atlas; 2017.

(Available from: www.theisn.org/global-atlas, accessed 2 September 2018).

3 Kopple JD. National kidney foundation K/DOQI clinical practice guidelines for nutrition in chronic renal failure. Am J Kidney Dis 2001; 37(1 Suppl 2): 66-70.

4 Campbell K, Ash S, Bauer J et al. Critical review of nutrition assessment tools to measure malnutrition in chronic kidney disease. Nutrition \& Dietetics 2007 ; 64(Supp 1): 23-30.

5 Pifer TB, Mccullough KP, Port FK et al. Mortality risk in hemodialysis patients and changes in nutritional indicators: DOPPS. Kidney Int 2002; 62: 2238-45.

6 Noordzij M, Korevaar JC, Boeschoten EW et al. The Kidney Disease Outcomes Quality Initiative (K/DOQI) Guideline for Bone Metabolism and Disease in CKD: association with mortality in dialysis patients. Am J Kidney Dis 2005; 46(5): 925-32.

7 Wright M, Jones C. Renal Association Clinical Practice Guideline on nutrition in CKD. Nephron Clin Pract 2011; 118(Suppl 1): 153-64.

$8 \quad$ Fouque D, Pelletier S, Mafra D, Chauveau P. Nutrition and chronic kidney disease. Kidney Int 2011; 80(4): 348-57.

$9 \quad$ Ash S, Campbell K, MacLaughlin $\mathrm{H}$ et al. Evidence based practice guidelines for the nutritional management of chronic kidney disease. Nutrition \& Dietetics 2006; 63: $35-45$.

10 Naylor HL, Jackson H, Walker GH et al. British Dietetic Association evidencebased guidelines for the protein requirements of adults undergoing maintenance haemodialysis or peritoneal dialysis. J Hum Nutr Diet 2013; 26(4): 315-28. published in final form at https://doi.org/10.1111/1747-0080.12528. 
Guidelines Protein requirements of Adults on Haemodialysis and Peritoneal Dialysis, 2011.

12 The Australian and New Zealand Renal Dietitians Workforce Planning Group. Workforce recommendations for renal dietitians in Australia and New Zealand, 2012 (Available from: https://daa.asn.au/wp-content/uploads/2018/11/Renal-DietitiansWorkforce-Recommendations.pdf, accessed 5 September 2016).

13 Queensland Health. Framework for Effective and Efficient Dietetics Services: An Evidenced-Based Demand Management Toolkit for Dietetics Services; 2017 (Available from: https://www.health.qld.gov.au, accessed 1 August 2017).

14 Lopes AA, Bragg-Gresham JL, Elder SJ et al. Independent and joint associations of nutritional status indicators with mortality risk among chronic hemodialysis patients in the Dialysis Outcomes and Practice Patterns Study (DOPPS). J Ren Nutr 2010; 20(4): 224-34.

15 Campell K, Ash S, Zabel R et al. Implementation of Standardized Nutrition Guidelines by Renal Dietitians Is Associated with Improved Nutrition Status. J Ren Nutr 2009; 19(2): 136-44.

16 Grimshaw J, Eccles M, Tetroe J. Implementing clinical guidelines: Current evidence and future implications. J Contin Educ Health Prof 2004; 24: 31 - S7. 17 Grol R, Wensing M. What drives change? Barriers to and incentives for achieving evidence-based practice. BMJ 2004; 180: 57-60.

18 French SD, Green SE, O'Connor DA et al. Developing theory-informed behaviour change interventions to implement evidence into practice: a systematic approach using the Theoretical Domains Framework. Implement Sci 2012; 7: 38. published in final form at https://doi.org/10.1111/1747-0080.12528. 
implemented evidence-based guidelines into practice? A survey of dietitians across Australia and New Zealand. J Ren Nutr 2012; 22(6): 584-91.

20 Straus S, Tetroe J, Graham I. Knowledge translation in health care. Moving from evidence to practice. Oxford: Wiley-Blackwell/BMJ Books, 2009.

21 Francis J, O'Connor D, Curran J. Theories of behaviour change synthesised into a set of theoretical groupings: introducing a thematic series on the theoretical domains framework. Implement Sci 2012; 7: 35.

22 Michie S, van Stralen M, West R. The behaviour change wheel: A new method for characterising and designing behaviour change interventions. Implement Sci 2011; 6: 42 .

23 Graham ID, Logan J, Harrison MB, Straus SE, Tetroe J, Caswell W. Lost in knowledge translation: time for a map? J Contin Educ Health Prof 2006; 26(1): 13-24. 24 Colquhoun $\mathrm{H}$, Leeman J, Michie S et al. Towards a common terminology: a simplified framework of interventions to promote and integrate evidence into health practices, systems and policies. Implement Sci 2014; 9: 51.

25 Johnson DW, Atai E, Chan M et al. KHA-CARI guideline: Early chronic kidney disease: detection, prevention and management. Nephrology (Carlton) 2013; 18(5): 340-50.

26 Wiggins KL, Harvey KS. A review of guidelines for nutrition care of renal patients. J Ren Nutr 2002; 12(3): 190-6.

27 Academy of Nutrition and Dietetics. About eNCPT 2017. (Available from: https://www.ncpro.org//default.cfm, accessed 10 February 2017).

28 Ottery FD. Patient-Generated Subjective Global Assessment In: The Clinical Guide to Oncology Nutrition ed. Chicago: The American Dietetic Association, 2000. 29 Albarracin D, Gillette J, Earl A et al. A Test of Major Assumptions About Behavior Change: A Comprehensive Look at the Effects of Passive and Active HIV- 
Prevention Interventions Since the Beginning of the Epidemic. Psychol Bull 2005; 131:

859-97.

30 Chang AM, Crowe L. Validation of scales measuring self-efficacy and outcome expectancy in evidence-based practice. Worldviews Evid Based Nurs 2011; 8:106-15.

This is the peer reviewed version of the following article: Mackay, H. J., Campbell, K. L., van der Meij, B. S., \& Wilkinson, S. A. (2019). Establishing an evidenced-based dietetic model of care in haemodialysis using implementation science. Nutrition and Dietetics, 76(2), 150-157, which has been published in final form at https://doi.org/10.1111/1747-0080.12528. 
Table 1. Overview of the application of the Knowledge to Action (KTA) framework, linked with identified barriers/enables for the proposed haemodialysis service, paired with interventions and strategies to operationalise interventions

\begin{tabular}{|c|c|c|c|c|}
\hline $\begin{array}{l}\text { Knowledge-to- } \\
\text { Action cycle }^{20}\end{array}$ & $\begin{array}{l}\text { Identified barriers (TDF } \\
\text { domain) }\end{array}$ & Enablers & $\begin{array}{l}\text { Intervention } \\
\text { function (from } \\
\mathrm{BCW})^{22}\end{array}$ & $\begin{array}{l}\text { Intervention function operationalised as } \\
\text { strategies }^{24}\end{array}$ \\
\hline $\begin{array}{l}\text { Identify } \\
\text { problem/identity, } \\
\text { review, select } \\
\text { knowledge }\end{array}$ & $\begin{array}{l}\text { No previous service therefore } \\
\text { assumed limited knowledge of } \\
\text { nutrition management during } \\
\text { dialysis for dietetics and nursing } \\
\text { staff } \\
\text { (Knowledge) }\end{array}$ & $\begin{array}{l}\text { Goals with guidelines to specify } \\
\text { details of nutrition care process and } \\
\text { workforce and external sites to } \\
\text { model or benchmark }\end{array}$ & $\begin{array}{l}\text { Psychological } \\
\text { capability }\end{array}$ & $\begin{array}{l}\text { 1. Comparison with alternate dialysis sites } \\
\text { dietetic service (modelling) } \\
\text { 2. Literature review informing procedures and } \\
\text { outcome measures from identified } \\
\text { evidence-based nutrition guidelines } \\
\text { 3. Knowledge and skills-based training with } \\
\text { nursing staff and dietetics }\end{array}$ \\
\hline $\begin{array}{l}\text { Assess barriers to } \\
\text { knowledge use }\end{array}$ & $\begin{array}{l}\text { No existing haemodialysis service } \\
\text { Time barrier for dietetics } \\
\text { (environmental context and } \\
\text { resources) }\end{array}$ & $\begin{array}{l}\text { Defined nutrition care 'goals' or } \\
\text { outcome measures from literature } \\
\text { Recommendations around dietetic } \\
\text { staffing as per literature }{ }^{12} \\
\text { Management support in providing } \\
\text { recommended staffing }\end{array}$ & $\begin{array}{l}\text { Psychological } \\
\text { capability } \\
\text { Physical } \\
\text { opportunity }\end{array}$ & $\begin{array}{l}\text { 1. Development of local documents detailing } \\
\text { NCP components for nutrition and } \\
\text { haemodialysis and incorporating into } \\
\text { development of local processes/procedures } \\
\text { 2. Creation of dietetic database with outcome } \\
\text { measures and prompts for review and } \\
\text { service provision } \\
\text { 3. Determining FTE and dietetic allocation } \\
\text { provided }\end{array}$ \\
\hline $\begin{array}{l}\text { Select, tailor, } \\
\text { implement } \\
\text { interventions }\end{array}$ & $\begin{array}{l}\text { No previous service therefore } \\
\text { assumed limited knowledge for } \\
\text { dietetics and nursing staff } \\
\text { (Knowledge, skills, beliefs about } \\
\text { capabilities) }\end{array}$ & $\begin{array}{l}\text { Interest in learning and engagement } \\
\text { from management and Mater } \\
\text { Education }\end{array}$ & $\begin{array}{l}\text { Psychological } \\
\text { capability } \\
\text { Physical } \\
\text { opportunity }\end{array}$ & $\begin{array}{l}\text { 1. Training packages for nursing staff and } \\
\text { dietitians } \\
\text { 2. Mentoring with identified experienced renal } \\
\text { dietitians } \\
\text { 3. Personal upskilling }\end{array}$ \\
\hline $\begin{array}{l}\text { Adapt knowledge to } \\
\text { local context }\end{array}$ & $\begin{array}{l}\text { No previous experience in } \\
\text { knowledge to action process for } \\
\text { the renal dietitian (Cognitive } \\
\text { Skills) }\end{array}$ & $\begin{array}{l}\text { Commencement of new service so } \\
\text { no previous local context or beliefs }\end{array}$ & $\begin{array}{l}\text { Psychological } \\
\text { capability }\end{array}$ & $\begin{array}{l}\text { 1. Professional development and personal } \\
\text { upskilling } \\
\text { 2.Peer reviewing } \\
\text { 3. Mentoring }\end{array}$ \\
\hline $\begin{array}{l}\text { Monitor knowledge } \\
\text { use }\end{array}$ & $\begin{array}{l}\text { No local dietetic processes in } \\
\text { place } \\
\text { (environmental context and } \\
\text { resources) }\end{array}$ & $\begin{array}{l}\text { Defined nutrition care process and } \\
\text { goals from literature }\end{array}$ & $\begin{array}{l}\text { Physical } \\
\text { capability }\end{array}$ & $\begin{array}{l}\text { 1. Monitoring of outcome measures } \\
\text { 2. Reporting outcome measure to key } \\
\text { stakeholders }\end{array}$ \\
\hline $\begin{array}{l}\text { Evaluate outcomes } \\
\text { Sustain knowledge }\end{array}$ & $\begin{array}{l}\text { No haemodialysis dietetic model } \\
\text { of care in place }\end{array}$ & $\begin{array}{l}\text { Dietetic department with focus in } \\
\text { evidence-base practice and regular }\end{array}$ & $\begin{array}{l}\text { Physical } \\
\text { opportunity }\end{array}$ & $\begin{array}{l}\text { 1. Creation of database with outcome } \\
\text { measures and prompts for review and }\end{array}$ \\
\hline
\end{tabular}

This is the peer reviewed version of the following article: Mackay, H. J., Campbell, K. L., van der Meij, B. S., \& Wilkinson, S. A. (2019). Establishing an evidenced-based dietetic model of care in haemodialysis using implementation science. Nutrition and Dietetics, 76(2), 150-157, which has been published in final form at https://doi.org/10.1111/1747-0080.12528.

This article may be used for non-commercial purposes in accordance with Wiley Terms and Conditions for Use of Self-Archived Versions 


\begin{tabular}{|l|l|l|l|l|}
\hline use & $\begin{array}{l}\text { (Environmental context and } \\
\text { resources) }\end{array}$ & $\begin{array}{l}\text { monitoring and evaluation processes } \\
\text { in place and encouraged }\end{array}$ & & $\begin{array}{l}\text { service provision } \\
\text { 2. Involvement in MDT processes such as } \\
\text { meetings, monthly blood review (with } \\
\text { Nephrologist, Pharmacist, nursing), } \\
\text { education strategies (nursing, patient, and } \\
\text { dietetics) } \\
\text { 3. Integration of haemodialysis dietetic } \\
\text { service into department reporting and } \\
\text { strategy planning }\end{array}$ \\
\hline
\end{tabular}

This is the peer reviewed version of the following article: Mackay, H. J., Campbell, K. L., van der Meij, B. S., \& Wilkinson, S. A. (2019). Establishing an evidenced-based dietetic model of care in haemodialysis using implementation science. Nutrition and Dietetics, 76(2), 150-157, which has been published in final form at https://doi.org/10.1111/1747-0080.12528.

This article may be used for non-commercial purposes in accordance with Wiley Terms and Conditions for Use of Self-Archived Versions 
Table 2. Malnutrition prevalence of haemodialysis patients at baseline, 6-months, and 12months following commencement at the service

\begin{tabular}{|c|c|c|c|c|}
\hline & Baseline & six-month & 12-month & P-value \\
\hline Total patients (N) & 32 & 22 & 20 & \\
\hline $\begin{array}{l}\text { PG-SGA Category (N) } \\
-\quad \text { A (Well nourished) }\end{array}$ & 23 (71.9\%) & 17 (77.3\%) & 16 (80.0\%) & $0.45^{1}$ \\
\hline $\begin{array}{l}\text { - } \quad \text { B (Moderately } \\
\text { malnourished) }\end{array}$ & $8(25.0 \%)$ & $4(22.7 \%)$ & $4(20.0 \%)$ & \\
\hline $\begin{array}{ll}\text { - } & \text { C (Severely } \\
\text { malnourished) }\end{array}$ & $1(3.1 \%)$ & 0 & & \\
\hline PG-SGA Score & $\begin{array}{l}6.2^{2}(95 \% \mathrm{Cl}: \\
4.6-7.8)\end{array}$ & $\begin{array}{l}5.3(95 \% \mathrm{Cl}: \\
4.6-7.8)\end{array}$ & $\begin{array}{l}4.8(95 \% \mathrm{Cl}: \\
2.8-6.7)\end{array}$ & $0.49^{3}$ \\
\hline \multicolumn{5}{|c|}{$\begin{array}{l}{ }^{1} \text { McNemar test based on two categories (PG-SGA A: well-nourished, PG-SGA } \\
\text { moderately and severely malnourished) with baseline and } 12 \text { months follow-up } \\
{ }^{2} \text { Missing score for } n=3\end{array}$} \\
\hline
\end{tabular}
published in final form at https://doi.org/10.1111/1747-0080.12528. 